Article

\title{
Prevalence, Epidemiological Characteristics, and Pharmacotherapy of Coronary Artery Disease among Patients with Atrial Fibrillation: Data from Jo-Fib Study
}

\author{
Hanna K. Al-Makhamreh ${ }^{1}$, Mohammed Q. Al-Sabbagh ${ }^{2,3, *} \mathbb{C}$, Ala $^{\prime}$ E. Shaban ${ }^{2} \mathbb{D}$, Abdelrahman F. Obiedat ${ }^{2}(\mathbb{D}$ \\ and Ayman J. Hammoudeh ${ }^{4}$ (i) \\ 1 Division of Cardiology, Department of Internal Medicine, Jordan University Hospital, University of Jordan \\ School of Medicine, Amman 11942, Jordan; HMAKHAMREH@hotmail.com \\ 2 University of Jordan School of Medicine, Amman 11942, Jordan; a.shabban@hotmail.com (A.E.S.); \\ aobiedat6@gmail.com (A.F.O.) \\ 3 Department of neurology, University of Kansas Medical Center, Kansas City, KS 66160, USA \\ 4 Department of Cardiology, Istishari Hospital, Amman 11184, Jordan; hammoudeh_ayman@yahoo.com \\ * Correspondence: mqs.sabbagh@gmail.com or Malsabbagh2@KUMC.edu; Tel.: +962-(79)-8944820
}

\section{check for}

updates

Citation: Al-Makhamreh, H.K.; Al-Sabbagh, M.Q.; Shaban, A.E.; Obiedat, A.F.; Hammoudeh, A.J. Prevalence, Epidemiological

Characteristics, and Pharmacotherapy of Coronary Artery Disease among Patients with Atrial Fibrillation: Data from Jo-Fib Study. Medicina 2021, 57, 605. https://doi.org/10.3390/ medicina57060605

Academic Editor: Fabio Angeli

Received: 21 May 2021

Accepted: 8 June 2021

Published: 11 June 2021

Publisher's Note: MDPI stays neutral with regard to jurisdictional claims in published maps and institutional affiliations.

Copyright: (c) 2021 by the authors. Licensee MDPI, Basel, Switzerland. This article is an open access article distributed under the terms and conditions of the Creative Commons Attribution (CC BY) license (https:/ / creativecommons.org/licenses/by/ $4.0 /)$.
Abstract: Background and Objectives: Patients with AF are at increased risk for Coronary Artery Disease (CAD) owing to their shared etiologies and risk factors. This study aimed to assess the prevalence, cardiovascular risk factors, and used medications of CAD in AF patients. Materials and Methods: This retrospective, case-control study utilized data from the Jordanian Atrial Fibrillation (Jo-Fib) registry. Investigators collected clinical features, history of co-existing comorbidities, CHA2DS2-VASc, and HAS BLED scores for all AF patients aged $>18$ visiting 19 hospitals and 30 outpatient cardiology clinics. A multivariable binary logistic regression was used to asses for factors associated with higher odds of having CAD. Results: Out of 2000 patients with AF, 227 (11.35\%) had CAD. Compared to the rest of the sample, those with CAD had significantly higher prevalence of hypertension $(82.38 \%$; $p<0.01)$, hypercholesterolemia $(66.52 \%, p<0.01)$, diabetes $(56.83 \%, p<0.01)$, and smoking $(18.06 \%$, $p=0.04)$. Patients with AF and CAD had higher use of anticoagulants/antiplatelet agents combination $(p<0.01)$ compared to the rest of the sample. Females had lower CAD risk than males $(\mathrm{OR}=0.35,95 \%$ CI: 0.24-0.50). AF Patients with dyslipidemia (OR $=2.5,95 \% \mathrm{CI}$ : $1.8-3.4)$, smoking (OR = 1.7, 95\% CI: 1.1-2.6), higher CHA2DS2-VASc score (OR = 1.5, 95\% CI: $1.4-1.7)$, and asymptomatic AF (OR = 1.9, 95\% CI: 1.3-2.6) had higher risk for CAD. Conclusions: Owing to the increased prevalence of CAD in patients with AF, better control of cardiac risk factors is recommended for this special group. Future studies should investigate such interesting relationships to stratify CAD risk in AF patients. We believe that this study adds valuable information regarding the prevalence, epidemiological characteristics, and pharmacotherapy of CAD in patients with AF.

Keywords: atrial fibrillation; coronary artery disease; Jordan; bleeding risk; thromboembolism

\section{Introduction}

Atrial fibrillation (AF) is the most commonly diagnosed cardiac arrhythmia worldwide [1]. The risk of developing AF in the general population is around $2 \%$, and it increases with age to the extent that it is found in $14 \%$ of those who are above 80 [2]. The risk of developing AF is especially higher in European ancestry, higher body weight, hypertension (HTN), diabetes mellitus (DM), and ischemic heart disease (IHD) [3,4]. AF is associated with worse mortality and morbidity outcomes worldwide; in a nationwide, populationbased study, all-cause mortality in AF patients was 4 times more than that in the general population [5]. Moreover, in patients with non-valvular AF, the annual risk for arterial thromboembolism, including stroke, is 5\%; this probability is even higher in patients older than 75 years and those with a previous history of stroke or transient ischemic attack (TIA) [5]. 
The prevalence of coronary artery disease (CAD) also increases with age, as it shares the common vascular risk factors of smoking, HTN, DM, and dyslipidemia with AF [6]. Patients with AF have higher prevalence of comorbid CAD in comparison to the general population; it is estimated that around $17 \%$ to $46.5 \%$ of patients with AF have a concurrent coronary artery disease (CAD) [7]. Myocardial infarctions (MI) might also predispose to AF or complicate the clinical course of preexisting AF [8]. It has been reported that one in ten patients presenting with MI had a previous history of AF [9]. Additionally, 6\% to $21 \%$ of patients with MI will develop AF [10]. Therefore, the development of AF is a poor prognostic factor post-MI both in the short and the long term [9]. On the other hand, there is increasing evidence that AF might predispose to CAD [11]. AF is associated with systemic signs of inflammation that might lead to a pro-thrombotic status that predisposes to CAD and ultimately myocardial infarction (MI)[12].

Coexisting CAD and AF (CAD-AF) is a challenging situation for clinicians to manage, especially in the case of acute coronary syndrome (ACS) due to the complexity of the used anticoagulants and antiplatelet agents, with the subsequent excessive chance of bleeding [6]. Therefore, there is a growing need for a better understanding of the general characteristics and risk factors of patients with CAD-AF.

In this study, we aimed to identify the prevalence of coronary artery disease (CAD) in AF patients in Jordan. In addition, we compared the clinical risk factors, treatment, and outcomes of CAD-AF patients to the rest of AF patients.

\section{Methodology}

\subsection{Study Design and Population}

This is a retrospective, case-control study utilizing baseline data from the Jordanian Atrial Fibrillation (Jo-Fib) registry that has the registration number of NCT03917992 [13]. The Jo-Fib study is a multi-centric, prospective, non-interventional, observational study registry. A total of 2000 patients aged $\geq 18$ years were consecutively enrolled from 19 Jordanian hospitals, 30 out-patient cardiology clinics and one hospital in the Palestinian Territories. Patients' enrollment started in May 2019 and concluded in November 2020.

\subsection{Measured Variables}

Data were collected using standardized clinical forms relaying on personal interviews and medical charts. A team of researchers, including but not limited to consultants, specialists, residents, and medical students, extracted patients' demographics, baseline clinical features, history of co-existing comorbidities, and medication history. The type of AF evident by 12-lead electrocardiography (EKG), Holter, or cardiac monitor was recorded for every patient upon enrollment. Participants were considered to have CAD if they have a documented acute coronary event, a history of typical/atypical cardiac chest pain with stress test findings, or coronary angiography findings suggestive of CAD. The collected data included patients' demographics (age, gender, height (in $\mathrm{cm}$ ), weight (in $\mathrm{Kg}$ ), and BMI $\left.\left(\mathrm{kg} / \mathrm{cm}^{2}\right)\right)$, symptoms of AF, co-morbidities (hypertension, diabetes, dyslipidemia, obstructive sleep apnea, heart diseases, stroke, chronic kidney disease, respiratory disease, thyroid disease, and cancer), history of systemic embolization, and medications history with emphasis on anticoagulants, antiplatelet agents, and antiarrhythmic medications. The researchers calculated the stroke risk using CHA2DS2-VASc score [14] and the bleeding risk using HAS BLED score for all patients [15]. Moreover, relevant Echocardiographic (ECHO) information (left ventricular ejection fraction (LVEF), left ventricular hypertrophy $(\mathrm{LVH})$, left atrial size (in $\mathrm{cm}$ ), presence of rheumatic heart disease, presence of pulmonary hypertension. and various other findings) were extracted.

\subsection{Data Analysis}

All extracted data were entered on Excel sheets and further imported into STATA (Stata Statistical Software: Release 16. College Station, TX: StataCorp LLC 4905 Lakeway Drive College Station, TX 77845, USA). Differences in sociodemographic characteristics, 
cardiac medical history, and used medications between patients with history of CAD and patients with no history of CAD were assessed using chi-square test for categorical variables and Student t-test for continuous variables. Alternatively, nonparametric tests such as Kruskal-Wallis test were utilized to assess differences in continuous variables in the case of non-normally distributed data. A multistage binary logistic regression analysis was also used to assess for factors correlated with higher risk of CAD in atrial fibrillation patients. The estat vif command was used to exclude variables with high variable inflation factor (VIF) to minimize multicollinearity. A $p$ value of $\leq 0.05$ was set to be a significant difference.

\subsection{Ethical Consideration}

The ethical approval of this study was granted from the Medical Research Ethical Committee and the Institutional Review Board (IRB) at the University of Jordan (ethical approval code: 10/2021/415, approval date: 29 December 2020). All participants were informed about the nature of the study, and a written consent was obtained from all patients. The authors assert that all procedures contributing to this work comply with the ethical standards of the relevant national and institutional committees on human experimentation and with the Helsinki Declaration of 1975, as revised in 2008.

\section{Results}

\subsection{Characteristics of the Sample}

Of the 2000 consecutively enrolled patients, $11.35 \%$ had CAD. The baseline clinical features are shown in Table 1 . A total of $64.47 \%$ of CAD-AF patients were males $(p<0.01)$, with the mean age of 68.7 years. A total of $22.21 \%$ of CAD-AF had a normal body mass index (BMI), 31.25\% were overweight, and 31.25\% were obese. Of the 227 AF patients with CAD, $82.38 \%$ had been diagnosed with hypertension $(p<0.01), 66.52 \%$ with hypercholesterolemia $(p<0.01), 56.83 \%$ with diabetes mellitus $(p<0.01)$, and $18.06 \%$ were cigarette smokers $(p=0.04)$.

Table 1. General demographic characteristics of 2000 patients with atrial fibrillation in terms of having coronary artery disease.

\begin{tabular}{|c|c|c|c|c|c|}
\hline Variable & Category & $N(\%)$ & History of CAD (\%) & No History of CAD (\%) & $p$ Value \\
\hline $\mathrm{N}$ & Total & 2000 & $227(11.35)$ & $1773(88.65)$ & \\
\hline Age & & $67.7 \pm 13.2 *$ & $68.7 \pm 11.7$ & $67.5 \pm 13.3$ & 0.2 \\
\hline \multirow[t]{3}{*}{ Sex } & & & & & $<0.01$ \\
\hline & Male & $933(46.65)$ & $147(64.76)$ & $786(44.33)$ & \\
\hline & Female & 1067 (53.35) & $80(35.24)$ & $987(55.67)$ & \\
\hline \multirow[t]{5}{*}{$\mathrm{BMI}^{*}$} & & & & & 0.14 \\
\hline & $<25$ & $426(23.4)$ & $46(22.1)$ & $380(23.5)$ & \\
\hline & $25-29$ & $659(36.1)$ & $65(31.3)$ & $594(36.8)$ & \\
\hline & $>30$ & $739(40.5)$ & 97 (46.6) & $642(39.7)$ & \\
\hline & Total & $1824(100)$ & $208(11.4)$ & $1616(88.6)$ & \\
\hline \multicolumn{6}{|c|}{ Medical history } \\
\hline & Hypertension & $1486(74.3)$ & $187(82.38)$ & $1299(73.26)$ & $<0.01$ \\
\hline & Diabetes mellitus & $882(44.1)$ & $129(56.83)$ & 753 (42.47) & $<0.01$ \\
\hline & Hypercholesterolemia & $878(43.9)$ & $151(66.52)$ & $727(41.0)$ & $<0.01$ \\
\hline & $\begin{array}{l}\text { Cigarette Smoking } \\
\text { (Current) }\end{array}$ & $273(13.66)$ & $41(18.06)$ & $232(13.08)$ & 0.04 \\
\hline
\end{tabular}

${ }^{*}$ Not all patients had weight and height measurements.

\subsection{Cardiac History and Pharmacotherapy}

Of the 227 CAD-AF patients, 34.81\% were shown to have paroxysmal AF, while $65.2 \%$ had non-paroxysmal AF $(p=0.6)$. A total of $94.28 \%$ of CAD-AF patients had non- 
valvular AF $(p=0.08)$. The cardiac history of AF patients is shown in Table 2. Palpitations $(p<0.01)$, fatigue $(p<0.01)$, dizziness $(p=0.03)$, and shortness of breath $(p<0.01)$ were more commonly found in non-CAD patients, while more CAD-AF patients experienced chest pain $(p<0.01)$ or were asymptomatic $(p<0.01)$. Heart failure $(p<0.01)$ and chronic kidney disease $(p=0.04)$ were more common in patients with CAD. However, left ventricular hypertrophy $(p<0.01)$ was observed more in non-CAD patients. CAD-AF patients had a lower left ventricular ejection fraction $(p<0.01)$, a higher CHA2DSVASc2 score $(p<0.01)$, and a higher HAS BLED score $(p<0.01)$.

Table 2. Cardiac history of 2000 patients with atrial fibrillation in terms of having coronary artery disease.

\begin{tabular}{|c|c|c|c|c|c|}
\hline Variable & Category & $N(\%)$ & History of CAD (\%) & No History of CAD (\%) & $p$ Value \\
\hline \multirow[t]{3}{*}{$\begin{array}{c}\text { Atrial Fibrillation } \\
\text { Type }\end{array}$} & & & & & 0.6 \\
\hline & Paroxysmal & 727 (36.35) & $79(34.81)$ & $648(36.55)$ & \\
\hline & Non-Paroxysmal & $1273(63.65)$ & $148(65.2)$ & $1125(63.45)$ & \\
\hline \multirow[t]{3}{*}{$\begin{array}{l}\text { Etiology of Atrial } \\
\text { Fibrillation }\end{array}$} & & & & & 0.08 \\
\hline & Valvular & $177(8.85)$ & $13(5.73)$ & $164(9.25)$ & \\
\hline & Non-valvular & $1823(91.15)$ & $214(94.28)$ & 1609 (90.75) & \\
\hline \multirow{7}{*}{$\begin{array}{l}\text { Atrial Fibrillation } \\
\text { Symptoms }\end{array}$} & Palpitations & $859(43)$ & $74(32.6)$ & $785(44.28)$ & $<0.01$ \\
\hline & Fatigue & $420(21)$ & $32(14.1)$ & $388(21.88)$ & $<0.01$ \\
\hline & Dizziness & $226(11.3)$ & $16(7.05)$ & $210(11.84)$ & 0.03 \\
\hline & SOB & $673(33.65)$ & $55(24.23)$ & $618(34.86)$ & $<0.01$ \\
\hline & Syncope & $45(2.25)$ & $3(1.33)$ & $42(2.37)$ & 0.31 \\
\hline & Chest pain & $34(1.7)$ & $11(4.85)$ & $23(1.3)$ & $<0.01$ \\
\hline & Asymptomatic & $591(29.5)$ & $98(43.18)$ & $492(27.75)$ & $<0.01$ \\
\hline \multirow{8}{*}{ Comorbid Diseases } & Stroke or systemic embolization & $313(15.65)$ & $34(14.98)$ & $279(15.74)$ & 0.77 \\
\hline & Heart failure & $467(23.35)$ & $69(30.4)$ & $398(22.45)$ & $<0.01$ \\
\hline & Left ventricular hypertrophy & 707 (39.1) & $60(26.44)$ & 647 (36.49) & $<0.01$ \\
\hline & Congenital heart disease & $11(0.55)$ & $2(0.89)$ & $9(0.51)$ & 0.5 \\
\hline & Pulmonary hypertension & $543(27.2)$ & $56(24.67)$ & 487 (27.47) & 0.37 \\
\hline & Sleep apnea & $76(3.8)$ & $6(2.65)$ & 70 (3.95) & 0.3 \\
\hline & Chronic kidney disease & $181(9)$ & $29(12.78)$ & $152(8.57)$ & 0.04 \\
\hline & Active malignancy & $117(5.85)$ & $9(3.97)$ & $108(6.09)$ & 0.2 \\
\hline \multirow[t]{4}{*}{$\begin{array}{l}\text { CHA2DS2-VASc } \\
\text { score }\end{array}$} & & & & & $<0.01$ \\
\hline & $\begin{array}{l}\text { Score } 1 \text { in women and } 0 \text { in men } \\
\text { (1) }\end{array}$ & $174(8.7)$ & $4(1.77)$ & $170(9.59)$ & \\
\hline & $\begin{array}{l}\text { Score } 2 \text { in women and } 1 \text { in men } \\
\text { (2) }\end{array}$ & $251(12.55)$ & $15(6.61)$ & $236(13.31)$ & \\
\hline & $\begin{array}{c}\text { Score } \geq 3 \text { in women and } \geq 2 \text { in } \\
\text { men ( } 3 \text { ) }\end{array}$ & $1575(78.75)$ & $208(91.63)$ & $1367(77.1)$ & \\
\hline \multirow[t]{5}{*}{ HAS-BLED score } & & & & & $<0.01$ \\
\hline & 0 & $266(13.3)$ & $11(4.85)$ & $255(14.38)$ & \\
\hline & 1 & $728(36.4)$ & $70(30.84)$ & $658(37.11)$ & \\
\hline & 2 & $623(31.15)$ & $89(39.21)$ & $534(30.12)$ & \\
\hline & $\geq 3$ & $383(19.15)$ & $57(25.12)$ & $326(18.39)$ & \\
\hline \multicolumn{6}{|l|}{$\begin{array}{l}\text { Echocardiographic } \\
\text { findings }\end{array}$} \\
\hline & LVEF * $^{*}$ & $53.6 \pm 12.4$ & $49.4 \pm 13.8$ & $54.2 \pm 12.1$ & $<0.01$ \\
\hline & Rheumatic mitral stenosis & $177(8.85)$ & $13(5.73)$ & $164(9.25)$ & 0.08 \\
\hline & Metallic prosthetic valve & $111(5.55)$ & $11(4.85)$ & $100(5.6)$ & 0.62 \\
\hline
\end{tabular}


Table 3 shows the pharmacotherapy used in our sample. Most of our sample (81.1\%) were using anticoagulants whether alone $(48.2 \%)$ or in combination with antiplatelet agents (33\%). Only $13.6 \%$ of our population used an antiplatelet agent alone, while $5.2 \%$ did not use any sort of antiplatelet agents or anticoagulants. Patients with CAD-AF showed significantly higher use of antiplatelet agents and anticoagulants/antiplatelet agents combination compared to the rest of the sample $(p<0.01)$. Out of the 1625 patients who used anticoagulants, 61.1\% used novel oral anticoagulants (NOACs) compared to vitamin $\mathrm{K}$ antagonists (38.9\%). Patients with CAD had significantly higher use of NOACs $(p=0.02)$. Regarding the used antiplatelet agents, the most commonly used regimen was aspirin (67.2\%) alone, clopidogrel (17.7\%), and dual antiplatelet therapy (13.7\%), respectively. Patients with CAD had significantly higher rates of clopidogrel and dual antiplatelet therapy use $(p<0.01)$.

Table 3. Pharmacotherapy of patients with atrial fibrillation in terms of having a history of CAD.

\begin{tabular}{|c|c|c|c|c|c|}
\hline Variable & Category & $N(\%)$ & History of CAD (\%) & No History of CAD (\%) & $p$ Value \\
\hline \multirow[t]{5}{*}{$\begin{array}{l}\text { Use of anticoagu- } \\
\text { lants/antiplatelet }\end{array}$} & & & & & $<0.01$ \\
\hline & None & $103(5.2)$ & $6(2.7)$ & $97(5.5)$ & \\
\hline & Anticoagulants alone & $964(48.2)$ & $55(24.2)$ & $909(51.3)$ & \\
\hline & Antiplatelet alone & $272(13.6)$ & $38(16.7)$ & $234(13.2)$ & \\
\hline & Anticoagulants+Antiplatelets & $661(33)$ & $128(56.4)$ & $533(30.1)$ & \\
\hline \multirow[t]{4}{*}{$\begin{array}{l}\text { The type of used } \\
\text { anticoagulation }\end{array}$} & & & & & 0.02 \\
\hline & Vitamin K Antagonists & $632(38.9)$ & $56(30.6)$ & $576(39.9)$ & \\
\hline & NOACs & $993(61.1)$ & $127(55.95)$ & $866(60.6)$ & \\
\hline & Total & $1625(100)$ & $183(11.3)$ & $1442(88.7)$ & \\
\hline \multirow[t]{6}{*}{$\begin{array}{l}\text { The type of used } \\
\text { Antiplatelet agent }\end{array}$} & & & & & $<0.01$ \\
\hline & Aspirin & $627(67.2)$ & $73(44)$ & $554(72.2)$ & \\
\hline & Clopidogrel & $165(17.7)$ & $45(27.1)$ & $120(15.7)$ & \\
\hline & Other antiplatelet & $13(1.4)$ & $2(1.2)$ & $11(1.4)$ & \\
\hline & Dual antiplatelet therapy * & $128(13.7)$ & $46(27.7)$ & $82(10.7)$ & \\
\hline & Total & $933(100)$ & $166(17.8)$ & $767(82.2)$ & \\
\hline \multirow{4}{*}{ Antiarrhythmics } & Beta blockers & $1603(80.15)$ & $191(84.14)$ & 1412 (79.64) & 0.11 \\
\hline & Amiodarone & $403(20.15)$ & $45(19.82)$ & $358(20.19)$ & 0.9 \\
\hline & $\mathrm{CCB}$ & $199(10)$ & $12(5.29)$ & $187(10.55)$ & 0.01 \\
\hline & Digoxin & $299(15)$ & $24(10.57)$ & $275(15.51)$ & 0.05 \\
\hline \multirow{3}{*}{ Others } & RAAS & $746(37.3)$ & $105(46.26)$ & $641(36.15)$ & $<0.01$ \\
\hline & Diuretics & $759(38)$ & $103(45.37)$ & $656(37)$ & 0.01 \\
\hline & Statins & 727 (36.35) & $151(66.52)$ & $576(32.49)$ & $<0.01$ \\
\hline
\end{tabular}

* It includes aspirin + another antiplatelet agent.

\subsection{Factors Associated with an Increased Risk of CAD in AF Patients}

Table 4 shows factors associated with an increased risk of CAD in AF patients. Females had a lower risk of CAD $(\mathrm{OR}=0.35, p<0.01,95 \% \mathrm{CI}: 0.24-0.50)$. AF Patients with dyslipidemia (OR = 2.5, $p<0.01,95 \% \mathrm{CI}$ : 1.8-3.4), history of smoking $(\mathrm{OR}=1.7, p=0.02$, 95\% CI: 1.1-2.6), higher CHA2DS2-VASc score (OR = 1.5, $p<0.01,95 \%$ CI: 1.4-1.7), low LVEF (OR $=0.98, p=0.01,95 \%$ CI: 0.97-0.99), congenital heart disease (OR = 6.4, $p=0.04$, 95\% CI: 1.09-37.9), or asymptomatic AF (OR = 1.9, $p<0.01,95 \%$ CI: $1.3-2.6)$ had a higher risk for $\mathrm{CAD}$. On the other hand, patients with history of stroke or systemic embolization $(\mathrm{OR}=0.3, p<0.01,95 \% \mathrm{CI}: 0.2-0.55)$, heart failure (OR $=0.57, p<0.01,95 \% \mathrm{CI}: 0.36-0.89)$, 
or left ventricular hypertrophy ( $\mathrm{OR}=0.5, p<0.01,95 \%$ CI0.36-0.7) had lower risk for CAD development.

Table 4. Multivariate binary logistic regression analyses for factors associated with higher risk of CAD.

\begin{tabular}{ccccc}
\hline Variable & Subgroups & OR & $p$ Value & 95\% Confidence Interval \\
\hline Sex & Male (Ref) & & & \\
\cline { 2 - 5 } & Female & 0.35 & $<0.01$ & $0.24-0.50$ \\
\hline Dyslipidemia & 2.5 & $<0.01$ & $1.8-3.4$ \\
\hline Stroke or systemic embolization & 0.3 & $<0.01$ & $0.2-0.55$ \\
\hline Heart failure & 0.57 & 0.01 & $0.36-0.89$ \\
\hline Left ventricular hypertrophy & 0.5 & $<0.01$ & $0.36-0.7$ \\
\hline Congenital heart disease & 6.4 & 0.04 & $1.09-37.9$ \\
\hline Smoking & 1.7 & 0.02 & $1.1-2.6$ \\
\hline Asymptomatic & 1.9 & $<0.01$ & $1.3-2.6$ \\
\hline CHADVASC score & 1.5 & $<0.01$ & $1.4-1.7$ \\
\hline
\end{tabular}

\section{Discussion}

Our study found that almost one out of every ten AF patient had coexisting CAD. The multivariable regression analysis showed that patients with history of smoking, HTN, $\mathrm{DM}$, and dyslipidemia had higher risk for CAD. Moreover, AF patients with history of stroke/systemic embolization or heart failure had lower risk of CAD development. These unexpected findings could be explained be survival bias; most of those with AF and any of these comorbidities died earlier, and only patients with excellent control of cardiac risk factors and compliance with medications survived to participate in this study [16]. Regarding pharmacotherapy, patients with CAD-AF patients showed a higher use of anticoagulants/antiplatelet agents combination.

In our sample, approximately one in each ten AF patients had CAD. Although we reported a lower prevalence of $\mathrm{CAD}$ in AF compared to the literature, it is still much higher than the prevalence of CAD in the general population, which is estimated to be around $2 \%[2,7]$. Some might argue that these lower numbers indicate favorable prognosis for AF or better control of cardiac risk factors in Jordan. These findings, however, might paradoxically be due to survival bias; CAD-AF patients die earlier because of poor riskfactors control [16]. Moreover, the co-presentation of CAD and AF could be deceiving, as CAD-AF patients in our sample were asymptomatic or presenting only with chest pain. Therefore, it is highly recommended to develop risk-estimation scores to stratify CAD risk in AF patients.

Our results showed that males had higher prevalence of CAD compared to females. It was reported that around $49 \%$ of males over 40 are at risk of CAD compared to $32 \%$ of females [17]. These differences could be attributed to biological factors, such as the cardiac protective role of female sex hormones. The increased risk of CAD in men could be explained, however, by the behavioral differences between males and females [18,19]. Studies have reported that males are more likely to delay their scheduled clinic visits; as a result, they present very lately. Overall, males have a lower perceived risk for illnesses, thus later health-seeking behaviors [18].

Chronic AF is associated with accelerated atherosclerosis due to the generalized inflammatory and pro-thrombotic status [12]. It is still unclear whether this systematic inflammation is due to AF solely or because of the higher prevalence of cardiovascular risk factors in AF patients [11]. Moreover, episodes of AF with rapid ventricular response might result in demand ischemia, predisposing CAD, and type $2 \mathrm{MI}$ attacks [20]. According to our results, smoking, HTN, DM, and dyslipidemia were all significantly more prevalent in CAD- 
AF patients. This is consistent with most regional studies about CAD risk factors [21-23]. In a study conducted in Iraq on patients undergoing coronary angiography for CAD, being a male, smoking, hypertension, hyperlipidemia, and a family history of CAD were all linked with premature CAD [21]. Another similar study in Jordan found that DM and smoking were associated with CAD, although they did not find any significant association between HTN or dyslipidemia with CAD [22]. Alsaud et al. found that most patients with CAD in Jordan have a cluster of more than one cardiac risk factor [23]. Therefore, cardiac risk factors should be controlled aggressively in patients with AF, as they are linked to higher risk of $\mathrm{CAD}, \mathrm{MI}$, and, subsequently, might worsen long-term morbidity and mortality.

Based on the American Heart Association/American College of Cardiology/European Society of Cardiology (ACC/AHA/ESC), antithrombotic therapy is a class IA recommendation to prevent stroke in AF patients with moderate to high risk to thromboembolism [24]. According to our results, around $80 \%$ of AF patients were using oral anticoagulants, with around $60 \%$ using NOACs and $40 \%$ using vitamin $\mathrm{K}$ antagonists. It is anticipated that the use of NOACs will increase with time, given the wide therapeutic index and more stable pharmacokinetic profiles compared to vitamin K antagonists. Nevertheless, vitamin $\mathrm{K}$ antagonists are still used in many developed countries, owing to their cheap price and coverage by insurance companies. Moreover, Vitamin K antagonists are the first line agents in AF of valvular etiologies, including patients with mild to moderate mitral stenosis as well as patients with prosthetic valves [25].

On the other hand, almost half of our sample was using some sort of antiplatelet therapy, with aspirin being the most commonly used one. Patients with CAD had significantly higher rate of dual antiplatelet therapy (DAPT) use. According the current ACC/AHA/ESC guidelines, daily aspirin is recommended for all patients with documented history of $\mathrm{CAD}$, as it has shown to significantly reduce the risk of future vascular events [26,27]. Other modifications to this regimen, in the forms of increasing the dose or adding other antiplatelet agents, might be utilized in patients with a cluster of other cardiovascular risk factors [28].

Interestingly, almost one-third of our sample were using the combination of anticoagulants and antiplatelet agents. Patients with CAD had significantly higher rates of using this combination. Although aspirin is not routinely recommended to be used in AF, it seems that many cardiologists in Jordan are aggressively anticoagulating AF patients, owing to the increased prevalence of cardiovascular risk factors in the Jordanian population [23]. Guidelines regarding antithrombotic treatment of CAD-AF are inconsistent, as they differ between North America and Europe [29]. For AF, oral anticoagulants are more effective compared to antiplatelet therapy in terms of stroke prevention [30]. However, antiplatelet agents (especially daily aspirin) are recommended in CAD [31]. In CAD-AF patients, both oral anticoagulants and antiplatelet agents should be ideally used. Unfortunately, this combination will increase the bleeding risk [32]. To aid in tailoring AF management, many scores and guidelines were proposed. The CHA2DS2-VASc is the most commonly used score to stratify AF patients in terms of future risks for stroke development [14]. Also, the HAS-BLED score is used to evaluate the risk of bleeding in patients being treated with anticoagulants for AF. Our results showed that patients with CAD had significantly higher CHA2DS2-VASc and HAS-BLED scores [15]. The double trouble of AF and CAD complications, including increased risk of thromboembolic events and bleeding in our sample, might result in a therapeutic dilemma for the treating physicians. Therefore, healthcare providers should follow a personalized approach with a multidisciplinary collaboration for each patient having these comorbidities.

To the best of our knowledge, this is the largest cohort-based study in the region addressing the relationship between AF and CAD. Nevertheless, the major limitation of our study is the observational, retrospective pattern of data collection. This raises the concerns of recall bias and precludes temporal evaluation of risk factors and outcomes. However, the personal interviews were double-checked with medical charts in order to minimize this potential limitation. Moreover, evaluating the actual risk of bleeding and thrombosis 
requires long-term, longitudinal studies with specific mortality and morbidity end points. Another potential limitation might arise from sampling; our study was performed in specialized cardiology clinics and medical centers which might not reflect the actual situation of AF patients. Nevertheless, owing to the nature of the healthcare system in Jordan, where patients usually bypass primary healthcare providers and seek specialty clinics directly, we think that our results reflect the actual prevalence of CAD in AF patients.

\section{Conclusions}

Our study showed that one in each ten AF patients had CAD. Smoking, HTN, DM, and dyslipidemia were all significantly more prevalent in patients with CAD-AF. Although they had a higher risk of bleeding (based on HAS-BLED score), patients with CAD-AF were using oral anticoagulants and antiplatelet agents more frequently. Physicians should evaluate the risk of CAD development in patients with $\mathrm{AF}$, and cardiac risk factors should be controlled accordingly, as concurrent, untreated AF and CAD carry poor outcomes. We believe that this study adds valuable information regarding the prevalence, epidemiological characteristics, and pharmacotherapy of CAD-AF patients. Longitudinal, long-term, prospective studies are required to obtain a better understanding of the course of CAD in AF, hopefully aiding in formulating more specific guidelines and scores for pharmacotherapy in this population.

Author Contributions: Conceptualization, H.K.A.-M., A.J.H. and A.F.O.; data analysis, M.Q.A.-S. and A.E.S.; writing - original draft preparation, M.Q.A.S., A.E.S. and A.F.O.; writing-review and editing, H.K.A.-M. and A.J.H.; supervision, H.K.A.-M. and A.J.H. All authors have read and agreed to the published version of the manuscript.

Funding: The author(s) received no specific funding for this work.

Institutional Review Board Statement: The study was conducted according to the guidelines of the Declaration of Helsinki, and approved by the Institutional Review Board of the University of Jordan (ethical approval code: 10/2021/415, approval date: 29 December 2020).

Informed Consent Statement: Informed consent was obtained from all subjects involved in the study.

Data Availability Statement: The data that support the findings of this study are available from The Jordan Atrial Fibrillation Study (Jo-Fib) but restrictions apply to the availability of these data, which were used under license for the current study, and so are not publicly available. Data are however available from the authors upon reasonable request and with permission of The Center for Strategic Studies.

Acknowledgments: The authors would like to thank the participating physicians who enrolled patients for the study (in alphabetical order): Abdallah Al-Kasasbeh, Abdullah Bani-Melhim, Abdul Nasser Almohamed, Ahmad Abdelsattar, Ahmad Abu Awwad, Ahmad Sbaih, Ahmad Tamari, Alaa Ababneh, Alanoud Hamada, Alia Khamis, Ali Abu-Romman, Ali Shakhatreh, Amer Asia, Amin Ibdah, Amr Adas, Assem Nammas, Aws Mukhtar, Ayad Al Qudsi, Basil Abdeen, Dalia Rawashdeh, Eid Abu-Eid, Eyadeh Madanat, Fahed Al-Karmi, Farah Al-Sayyed, Farah Halaweh, Fatima Al Nadi, Hana Al-Raie, Haneen Shawer, Hanin Saleh, Hanna Makhamreh, Hazem Abu Asbeh, Hisham Amin, Ibrahim Abbadi, Ibrahim Jarrad, Islam Abu Sedo, Islam Obeidat, Ismail Hamam, Kais Bilbeisi, Lama Khader,Leen Sharqawi, Liza Shaban, Lubaba Qabbaa, Lubna Haikal, Lubaba Qabbaah, Mahmoud Izraiq, Marwan Nemri, Marwan Al Sultan, Mo'ath Alfawar'a, Mohammad Abdah, Mohammad Afeef, Mohammad Al-Jawabreh, Mohammad Ali Jarrah, Mohammad Hani, Mohammad Kraishan, Mohannad Ababneh, Mohamad Jarrah, Mohammad Jabary, Munir Zaqqa, Mustafa Jammal, Myassar Amr, Noor Al-Badaineh, Obada Mansour, Odai Khasawneh, Oday Abu Ajameyyeh, Omar Abu Slieh, Omar Obeidat, Omar Salaymeh, Omran Abukhalaf, Osama Oudeh, Qusai Abu Ajameyyeh, Raed Awaisheh, Rami Bataineh, Rashid Abdah, Sa'ad Al-Muhaisen, Saed Al Ghamri, Safa' Amro, Said Meri, Saleh Ghamdi, Sukaina Rawashdeh, Sara Al-Thunibat, Sara Younis, Sharif Adwan, Sulafa Saffarini, Tamer Salhab, Tawfiq Barqawi, Yahya Ismail, Yousef Khader, Zaid Dabash, Zeina Abu-Orabi, Zainab Salahat, Zainah Matani, Zakaria Shkoukani, and Zakariya Al-Hasanat.

Conflicts of Interest: The authors declare that they have no competing interest. 


\section{References}

1. Morillo, C.A.; Banerjee, A.; Perel, P.; Wood, D.; Jouven, X. Atrial fibrillation: The current epidemic. J. Geriatr. Cardiol. 2017, 14, 195-203. [PubMed]

2. Kirchhof, P.; Benussi, S.; Kotecha, D.; Ahlsson, A.; Atar, D.; Casadei, B.; Castella, M.; Diener, H.C.; Heidbuchel, H.; Hendriks, J.; et al. 2016 ESC Guidelines for the management of atrial fibrillation developed in collaboration with EACTS. Europace 2016, 18, 1609-1678. [CrossRef] [PubMed]

3. Benjamin, E.J.; Muntner, P.; Alonso, A.; Bittencourt, M.S.; Callaway, C.W.; Carson, A.P.; Chamberlain, A.M.; Chang, A.R.; Cheng, S.; Das, S.R.; et al. Heart Disease and Stroke Statistics-2019 Update: A Report From the American Heart Association. Circulation 2019, 139, e56-e528. [CrossRef]

4. Benjamin, E.J.; Levy, D.; Vaziri, S.M.; D’agostino, R.B.; Belanger, A.J.; Wolf, P.A. Independent Risk Factors for Atrial Fibrillation in a Population-Based Cohort: The Framingham Heart Study. JAMA 1994, 271, 840-844. [CrossRef] [PubMed]

5. Lee, E.; Choi, E.-K.; Han, K.-D.; Lee, H.; Choe, W.-S.; Lee, S.-R.; Cha, M.-J.; Lim, W.-H.; Kim, Y.-J.; Oh, S. Mortality and causes of death in patients with atrial fibrillation: A nationwide population-based study. PLoS ONE 2018, 13, e0209687. [CrossRef] [PubMed]

6. Violi, F.; Soliman, E.Z.; Pignatelli, P.; Pastori, D. Atrial Fibrillation and Myocardial Infarction: A Systematic Review and Appraisal of Pathophysiologic Mechanisms. J. Am. Heart Assoc. 2016, 5, e003347. [CrossRef]

7. Michniewicz, E.; Mlodawska, E.; Lopatowska, P.; Tomaszuk-Kazberuk, A.; Malyszko, J. Patients with atrial fibrillation and coronary artery disease-Double trouble. Adv. Med. Sci. 2018, 63, 30-35. [CrossRef]

8. Theodorakis, G. Coronary artery disease and atrial fibrillation. Hell. J. Cardiol. 2017, 58, 213-214. [CrossRef]

9. Schmitt, J.; Duray, G.; Gersh, B.J.; Hohnloser, S.H. Atrial fibrillation in acute myocardial infarction: A systematic review of the incidence, clinical features and prognostic implications. Eur. Heart J. 2009, 30, 1038-1045. [CrossRef]

10. Jabre, P.; Jouven, X.; Adnet, F.; Thabut, G.; Bielinski, S.J.; Weston, S.A.; Roger, V.L. Atrial fibrillation and death after myocardial infarction: A community study. Circulation 2011, 123, 2094-2100. [CrossRef]

11. O'Neal, W.T.; Soliman, E.Z.; Howard, G.; Howard, V.J.; Safford, M.M.; Cushman, M.; Zakai, N.A. Inflammation and hemostasis in atrial fibrillation and coronary heart disease: The REasons for Geographic And Racial Differences in Stroke study. Atherosclerosis 2015, 243, 192-197. [CrossRef]

12. Guo, Y.; Lip, G.Y.H.; Apostolakis, S. Inflammation in atrial fibrillation. J. Am. Coll. Cardiol. 2012, 60, 2263-2270. [CrossRef] [PubMed]

13. The Jordan Atrial Fibrillation Study: Baseline Risk Scores and One Year Outcome-Full Text View-ClinicalTrials.gov. Available online: https:/ / clinicaltrials.gov/ct2/show / NCT03917992 (accessed on 6 November 2020).

14. Lip, G.Y.H.; Nieuwlaat, R.; Pisters, R.; Lane, D.A.; Crijns, H.J.G.M.; Andresen, D.; Camm, A.J.; Davies, W.; Capucci, A.; Olsson, B.; et al. Refining clinical risk stratification for predicting stroke and thromboembolism in atrial fibrillation using a novel risk factor-based approach: The Euro Heart Survey on atrial fibrillation. Chest 2010, 137, 263-272. [CrossRef] [PubMed]

15. Pisters, R.; Lane, D.A.; Nieuwlaat, R.; De Vos, C.B.; Crijns, H.J.G.M.; Lip, G.Y.H.; Andresen, D.; Camm, A.J.; Davies, W.; Capucci, A.; et al. A novel user-friendly score (HAS-BLED) to assess 1-year risk of major bleeding in patients with atrial fibrillation: The euro heart survey. Chest 2010, 138, 1093-1100. [CrossRef]

16. Delgado-Rodríguez, M.; Llorca, J. Bias. J. Epidemiol. Community Health 2004, 58, 635-641. [CrossRef]

17. Wenger, N.K. Clinical characteristics of coronary heart disease in women: Emphasis on gender differences. Cardiovasc. Res. 2002, 53, 558-567. [CrossRef]

18. Al-Sabbagh, M.Q.; Al-Ani, A.; Mafrachi, B.; Siyam, A.; Isleem, U.; Massad, F.I.; Alsabbagh, Q.; Abufaraj, M. Predictors of adherence with home quarantine during COVID-19 crisis: The case of health belief model. Psychol. Health Med. 2021. [CrossRef] [PubMed]

19. Umubyeyi, A.; Mogren, I.; Ntaganira, J.; Krantz, G. Help-seeking behaviours, barriers to care and self-efficacy for seeking mental health care: A population-based study in Rwanda. Soc. Psychiatry Psychiatr. Epidemiol. 2016, 51, 81-92. [CrossRef]

20. Sandoval, Y.; Smith, S.W.; Thordsen, S.E.; Apple, F.S. Supply/demand type 2 myocardial infarction should we be paying more attention? J. Am. Coll. Cardiol. 2014, 63, 2079-2087. [CrossRef]

21. Mohammad, A.M.; Jehangeer, H.I.; Shaikhow, S.K. Prevalence and risk factors of premature coronary artery disease in patients undergoing coronary angiography in Kurdistan, Iraq. BMC Cardiovasc. Disord. 2015, 15, 155. [CrossRef]

22. Al-Shudifat, A.E.; Johannessen, A.; Azab, M.; Al-Shdaifat, A.; AbuMweis, S.S.; Agraib, L.M.; Tayyem, R.F. Risk factors for coronary artery disease in patients undergoing elective coronary angiography in Jordan. BMC Cardiovasc. Disord. 2017, 17, 183. [CrossRef] [PubMed]

23. Alsaud, W.; Tabbaa, M.J.; Kasabri, V.N.; Suyagh, M.F.; Alsamen, M.A.A.; Haddad, H.M.; Alshweki, A.O. Prevalence of cardiovascular Diseases Risk Factors Among Jordanians. J. Saudi Heart Assoc. 2020, 32, 324. [CrossRef] [PubMed]

24. Fuster, V.; Rydén, L.E.; Asinger, R.W.; Cannom, D.S.; Crijns, H.J.; Frye, R.L.; Halperin, J.L.; Kay, G.N.; Klein, W.W.; Lévy, S.; et al. ACC/AHA/ESC guidelines for the management of patients with atrial fibrillation: Executive summary. A report of the American College of Cardiology/American Heart Association Task Force on Practice Guidelines and the European Society of Cardiology Committee for Practice Guidelines and Policy Conferences (Committee to Develop Guidelines for the Management of Patients with Atrial Fibrillation). Circulation 2001, 104, 2118-2150. [PubMed] 
25. Mekaj, Y.H.; Mekaj, A.Y.; Duci, S.B.; Miftari, E.I. New oral anticoagulants: Their advantages and disadvantages compared with vitamin K antagonists in the prevention and treatment of patients with thromboembolic events. Ther. Clin. Risk Manag. 2015, 11, 967-977. [CrossRef] [PubMed]

26. Ittaman, S.V.; VanWormer, J.J.; Rezkalla, S.H. The role of aspirin in the prevention of cardiovascular disease. Clin. Med. Res. 2014, 12, 147-154. [CrossRef] [PubMed]

27. Arnett, D.K.; Blumenthal, R.S.; Albert, M.A.; Buroker, A.B.; Goldberger, Z.D.; Hahn, E.J.; Himmelfarb, C.D.; Khera, A.; Lloyd-Jones, D.; McEvoy, J.W.; et al. 2019 ACC/AHA Guideline on the Primary Prevention of Cardiovascular Disease: Executive Summary: A Report of the American College of Cardiology/American Heart Association Task Force on Clinical Practice Guidelines. Circulation 2019, 140, e563-e595. [CrossRef] [PubMed]

28. Sharma, R.; Kumar, P.; Prashanth, S.P.; Belagali, Y. Dual Antiplatelet Therapy in Coronary Artery Disease. Cardiol. Ther. 2020, 9 , 349-361. [CrossRef] [PubMed]

29. Huber, K.; Juhani Airaksinen, K.; Cuisset, T.; Marín, F.; Rubboli, A.; Lip, G.Y.H. Antithrombotic therapy in patients with atrial fibrillation undergoing coronary stenting: Similarities and dissimilarities between north America and Europe. Thromb. Haemost. 2011, 106, 569-571. [PubMed]

30. Site, H.G. Clopidogrel plus aspirin versus oral anticoagulation for atrial fibrillation in the Atrial fibrillation Clopidogrel Trial with Irbesartan for prevention of Vascular Events (ACTIVE W): A randomised controlled trial. Lancet 2006, 367, 1903-1912. [CrossRef]

31. Leon, M.B.; Baim, D.S.; Popma, J.J.; Gordon, P.C.; Cutlip, D.E.; Ho, K.K.L.; Giambartolomei, A.; Diver, D.J.; Lasorda, D.M.; Williams, D.O.; et al. A Clinical Trial Comparing Three Antithrombotic-Drug Regimens after Coronary-Artery Stenting. N. Engl. J. Med. 1998, 339, 1665-1671. [CrossRef]

32. Hess, C.N.; Broderick, S.; Piccini, J.P.; Alexander, K.P.; Newby, L.K.; Shaw, L.K.; Mahaffey, K.W.; Alexander, J.H.; Peterson, E.D.; Granger, C.B.; et al. Antithrombotic therapy for atrial fibrillation and coronary artery disease in older patients. Am. Heart J. 2012, 164, 607-615. [CrossRef] [PubMed] 